\title{
Unknown Cellular or Molecular Mechanism
}

National Cancer Institute

\section{Source}

National Cancer Institute. Unknown Cellular or Molecular Mechanism. NCI Thesaurus.

Code C40551.

An Unknown Cellular or Molecular Interaction consists of an activity or association of biologic molecules, complexes, or subcellular components that is currently undetermined. 